\title{
O DIAGNÓSTICO JURÍDICO DAS OBRAS CIVIS
}

\author{
THE LEGAL DIAGNOSIS OF CIVIL CONSTRUCT
}

Taniza Conceição da Silva ${ }^{1}$

\section{RESUMO}

Discorre a respeito dos ditames legais referente as obras civis no contexto ambiental. Apresenta ocorrências na cidade de Florianópolis, capital, bem como a cidade de Caçador, ambas no estado de Santa Catarina, região sul do Brasil. Apresenta os princípios da precaução, prevenção e Constitucional do desenvolvimento sustentável. Reflete a respeito da responsabilidade social e ambiental da pessoa jurídica além da teoria do risco integral. Destaca a necessidade dos empreendedores da construção civil se resguardar previamente através de assessoria especializada, evitando a insegurança que o seguimento vem enfrentando ao que se reporta a própria proteção do meio ambiente e a sadia qualidade de vida local, seja esta humana, fauna e ou flora. Além do cumprimento sócio-ambiental inerente a este tema.

Palavras-Chave: Obra Civil, Diagnóstico Jurídico, Meio Ambiente, Desenvolvimento Sustentável.

\section{ABSTRACT}

Discusses the legal dictates regarding civil works in the environmental context. It presents occurrences in the city of Florianópolis, capital, as well as the city of Caçador, both in the state of Santa Catarina, southern region of Brazil. It presents the Precautionary, Preventive and Constitutional Principles of Sustainable Development. It reflects on the social and environmental responsibility of the legal person besides the integral risk theory. Emphasis is placed on the need for construction entrepreneurs to safeguard themselves in advance through specialized advice, avoiding the insecurity that the monitoring is facing to what is reported the very protection of the environment and the healthy quality of local life, be it human, fauna and flora. In addition to the socio-environmental

\footnotetext{
${ }^{1}$ Especialista em Direito Ambiental e Urbanístico pela Anhanguera. Advogada - OAB/RS $98640 B$. Bacharel em Direito pela UCPEL/RS. Email: taniza.silva@gmail.com.
} 
compliance.

Keywords: Civil Construct, Legal Diagnosis, Environment, Sustainable Development.

\section{INTRODUÇÃO}

O Brasil, país proeminentemente agrário até o início do século XX, teve em meados dos anos sessenta o nascimento de um crescente e substancioso êxodo rural, fazendo com que os centros urbanos se desenvolvessem em uma velocidade expressiva. Maricato (2001):

\footnotetext{
O Brasil, como os demais países da América Latina, apresentou intenso processo de urbanização, especialmente na segunda metade do século XX. Em 1940, a população urbana era de 26,3\% do total. Em 2000 ela é de $81,3 \%$. Esse crescimento se mostra mais impressionante ainda se lembrarmos os números absolutos: em 1940 a população que residia nas cidades era de 18,8 milhões de habitantes e em 2000 ela é de aproximadamente 138 milhões. Constatamos, portanto, que em sessenta anos os assentamentos urbanos foram ampliados de forma a abrigar 125 milhões de pessoas. Considerando a ultima década do século XX, as cidades brasileiras aumentaram em 22.718 .968 pessoas, isso equivale a mais da metade da população do Canadá ou a um terço da população da França.
}

O forte êxodo rural não foi recepcionado pela administração pública de forma adequada, sobretudo nos quesitos pertinentes ao planejamento urbano. As dimensões das cidades foram sendo expandidas com a criação de novos bairros e vilas sob a omissão da administração pública, a qual não assegurou para esses novos moradores nem ao menos as condições mínimas necessárias de habitação, quiçá as condições ambientais foram respeitadas (até porque estas nem eram consideradas existentes) sendo essas cidades construídas de forma desordenada, clandestina. Nesse contexto, a favelização dos morros e encostas pelos moradores de baixa renda tornou-se uma constante. A respeito esclarece Maricato (2001):

O processo de urbanização se apresenta como uma máquina de produzir favelas e agredir o meio ambiente. O número de imóveis ilegais na maior parte das grandes cidades é tão grande que, inspirado na interpretação de Arantes e Schwatz sobre Brecht, podemos repetir que "a regra se tornou exceção e a exceção a regra". A cidade legal (cuja produção é hegemônica e capitalista) caminha para ser, cada vez mais espaço da minoria. 
A construção civil, neste cenário de urbanização expressiva, evidentemente teve que se adaptar a crescente demanda, de forma ágil, tornandose um seguimento econômico de futuro promissor. Muitas cidades brasileiras na atualidade estão em acelerado crescimento, onde a construção civil é seguimento dos mais promissores e que mais demandam trabalho. Paralelo a isso, a qualidade de vida, a preservação do meio ambiente significativamente vem sendo ignorada ou tratada de forma tímida, como questão de segunda ordem em relação à satisfação do retorno financeiro que a construção civil proporciona. Porém, o referido seguimento econômico não pode se esquivar de seus deveres ambientais, os quais possuem caráter de direito fundamental, ditado pela Constituição Federal de 88 e demais leis infraconstitucionais pertinentes.

\section{O MEIO AMBIENTE: DITAMES CONSTITUCIONAIS}

No âmbito constitucional brasileiro, a inclusão das questões ambientais é recente, pois ocorreu apenas com a promulgação da carta de 88. Prevê em seu artigo 225 a obrigatoriedade da integralidade, aqui entendidos como administração pública e todos os seguimentos da sociedade a preservação do meio ambiente. Cite-se:

Art. 225. Todos têm direito ao meio ambiente ecologicamente equilibrado, bem de uso comum do povo e essencial à sadia qualidade de vida, impondo-se ao Poder Público e à coletividade o dever de defendê-lo e preservá-lo para os presentes e futuras gerações.

Sobre o assunto, José Afonso da Silva (apud Reis, 2008) esclarece:

O assunto integra o título da ordem social, onde se estatui que todos têm direito ao meio ambiente ecologicamente equilibrado, bem de uso comum do povo e essencial à sadia qualidade de vida, impondo-se ao poder público e à coletividade o dever de defendê-lo e preservá-lo para as presentes e futuras gerações (art.225). É um campo que integra, na sua complexidade, a disciplina urbanística, mas se revela como social, na medida em que sua concreção importa em prestação do poder público.

Após análise prévia da Carta Magna, necessária breve exposição dos princípios correlatos e oportunos ao estudo em que a reflexão se propõe, como forma de nortear e ampliar o entendimento do que engloba o assunto, sua 
dimensão e problemáticas correlatas.

\section{PRINCÍPIO DA PRECAUÇÃO}

Não obstante a falta de uma certeza científica concreta, a coletividade (incluindo cidadãos e poder público) deve primar sempre pela sustentabilidade, pela qualidade de vida, pela proteção ao meio ambiente. Tem-se por tal preceito o princípio da precaução. Tal princípio impõe-nos o impedimento de toda e qualquer atividade que tenha a possiblidade de ferir o meio ambiente, mesmo que, de forma hipotética, evidenciando o manto de importância de primeira ordem que cobre as questões ambientais. Nesse diapasão, acrescenta Colombo, 2011):

Entretanto, o princípio da precaução é prioritariamente utilizado quando o risco de degradação do meio ambiente é considerado irreparável ou o impacto negativo ao meio ambiente é tamanho que exige a aplicação imediata das medidas necessárias à preservação.

O que se almeja com o referido princípio é que o meio ambiente não permaneça vulnerável às situações que possam ser catastróficas, apenas por se desconhecer ao certo quais exatamente serão essas sequelas, pois a natureza, o meio em que se vive deve ser protegido de qualquer lesão que possa vir a sofrer. Desta forma, muito antes da concretização do dano, trabalha-se com o risco possível, o risco em abstrato, eis que o conhecimento e a ciência estão em eterna mutação. Tal princípio consta implicitamente na Constituição Federal de 1988. Machado (apud COLOMBO, 2011):

No princípio da precaução previne-se porque não se pode saber quais as consequências que determinado ato, ou empreendimento, ou aplicação científica causarão ao meio ambiente no espaço e/ou no tempo, quais os reflexos ou consequências. Há incerteza científica não dirimida (www.ecoambiental.com.br/principal/princípios).

Embora em um dado momento não haja certeza a respeito das possíveis consequências negativas que um fato possa trazer ao meio ambiente, da simples possibilidade de lesão ao meio ambiente nasce a obrigatoriedade de medidas protetivas ao meio ambiente, seja através de autos de infração emitidos pela administração pública competente, embargos judiciais de obras e até mesmo demolições dentre tantos outros óbices de ordem econômica que a construção 
civil possa sofrer.

\section{PRINCÍPIO DA PREVENÇÃO}

Diferente do Princípio da Precaução, o da Prevenção preocupa-se com o risco em concreto ao meio ambiente, e, nas palavras de Machado (apud Colombo, 2011), aqui "previne-se porque se sabe quais as consequências de se iniciar determinado ato", havendo nexo causal entre a conduta e resultado propriamente dito. Desta forma, tal princípio defende que a lesão conhecida deve ser evitada, tanto quanto for possível, sempre em prol do meio ambiente ${ }^{2}$.

\section{PRINCÍPIO CONSTITUCIONAL DO DESENVOLVIMENTO SUSTENTÁVEL}

O desenvolvimento econômico de uma sociedade é pilar de suma importância, não s podendo se cogitar o retrocesso da sociedade a tempos remotos. Porém, o fato é que a humanidade tem que aprender a transformar o desenvolvimento econômico em um aliado à vida sadia e sustentável, e não seu algoz. O desenvolvimento econômico é bem construído ao longo da própria história da sociedade, não obstante muitas vezes é perseguido em detrimento dos direitos da dignidade da pessoa humana, dos direitos ambientais e assim por diante. Desta forma, a questão econômica é problematizada quando se contrapõe ao meio ambiente, sua manutenção e a garantia da permanência da vida sadia. Tal problemática é costumeira no capitalismo desenfreado que vivemos, através das atenções direcionadas apenas à preocupação do desenvolvimento econômico em detrimento da sustentabilidade, do meio ambiente, condicio sine qua non para que a vida na terra, incluindo a do próprio homem permaneça garantida para o futuro.

No Brasil a situação não é diferente, eis que em um modo geral os seguimentos econômicos relutam em se conscientizar que a proteção ambiental

\footnotetext{
2 Já a atuação preventiva é o ponto central do direito ambiental, e se traduz numa frase do senso comum: "Mais vale prevenir do que remediar." (MORATO LEITE, 2000, p. 52). Ou seja, a degradação do meio ambiente deve ser evitada antes de sua concretização e não apenas combater e/ou minimizar os efeitos dessa degradação. COLOMBO, Silvana Bendler. O Princípio da Precaução do Direito Ambiental. Disponível em http://www.franca.unesp.br/direitoambiental.pdf. Acesso em 28 de novembro de 2011.
}

Ignis | Caçador | v.6 | n.1 | p. 143-169 | jan./abr. 2017 
não é adversária ao desenvolvimento econômico, resistindo ao entendimento que uma sociedade moderna, avançada e próspera não pode evoluir sem que os pilares sociais, econômicos e ambientais andem em harmonia.

O mesmo ocorre com os seguimentos ligados à urbanização das cidades brasileiras, cidades estas que em sua maioria, foram criadas de forma desordenada, sem critérios técnicos necessários a sadia qualidade urbana, com esgotos lançados diretamente nas águas, e edificações feitas ao bel prazer, e em qualquer lugar, sem o mínimo de critério técnico.

Atualmente o ramo da construção civil, viciada na postura de execução dissociada dos ditames mínimos necessários para sustentabilidade da biota local, vem frequentemente sofrendo as consequências legais pela ausência de apoio especializado, sobretudo do apoio que o advogado militante na área ambiental pode the prestar. Não raro deparamo-nos com empreendimentos em áreas impróprias, até mesmo avançando por sobre áreas de preservação permanente, por negligência do gestor do empreendimento, mas também pela falta de informação e ou informações errôneas por parte dos próprios órgãos, os quais carecem de equipes preparadas e com conhecimento especializado, o que fatalmente gerará problemas de diversas ordens.

\section{A RESPONSABILIDADE SOCIAL DA PESSOA JURÍDICA}

Antes mesmo de adentrarmos na responsabilidade social de pessoa Jurídica, importante o entendimento do que seja a responsabilidade social da propriedade. Trata-se da obrigatoriedade que a propriedade privada possui de respeitar os interesses e direitos de uma coletividade em seus inúmeros enfoques. A ideia de direito de propriedade absoluta sob todas as coisas está por demais ultrapassada à luz do ordenamento jurídico. Desta forma, a autonomia conferida ao proprietário sobre a coisa adquirida atualmente é mitigada, limitada aos direitos que por si só possuem superior grandeza ao Direito Privado, quais sejam, os Direitos Sociais.

A função social da propriedade está explicitada no artigo 5o da Constituição Federal de 88 em seu inciso XXII. Na mesma, no capítulo que trata da ordem econômica e financeira, traz dentre os princípios basilares a função social da 
propriedade (art. 170, III) ${ }^{3}$. A partir desse entendimento esclarece-se que, a cada vez que a referida propriedade macular a sua função social, fatalmente será responsabilizada. É a responsabilidade social da pessoa jurídica.

Desta forma, se o empreendimento agir de forma descompromissada sob o ponto de vista social (englobando aqui as questões ambientais e urbanísticas), fatalmente Ihe recairá consequências negativas, por estre transcendendo o limiar existente entre o seu direito à propriedade, a livre iniciativa econômica e a obrigação de respeitar o meio ambiente. Já àqueles empreendimentos em acordo com as leis ambientais não serão imputados entraves, pelo contrário; serão beneficiados inclusive com incentivos fiscais, caso promovam iniciativas sócio ambientais. Como se vê a função social da propriedade possui grande abrangência, englobando desta feita o dever de garantir uma economia sustentável que não lese o ambiente 4 .

\section{A RESPONSABILIDADE AMBIENTAL DA PESSOA JURÍDICA}

Conforme a autora em sua monografia", "a Carta Magna, em seu artigo 225 , § 3 o determina a aplicabilidade de sanções administrativas e penais a quem, pessoa física ou jurídica apresentar conduta e ou possuir atividades lesivas ao meio ambiente, além da obrigação de reparação do dano causado". Cite-se o referido parágrafo constitucional:

$\S 3$ - As condutas e atividades consideradas lesivas ao meio ambiente sujeitarão os infratores, pessoas físicas ou jurídicas, a sanções penais e administrativas, independentemente da obrigação de reparar os danos causados. ${ }^{6}$

3 BRASIL, Constituição Federal de 88. Disponível em: http://www.planalto.gov.br/ccivil_03/constituicao/constituicao.htm. Acesso em 1 o de março de 2015.

${ }^{4}$ SILVA, T. C. da. A Consultoria Jurídica: Diagnóstico de Viabilidade de Empreendimentos urbanos em Florianópolis. Monografia (Pós-graduação em Direito Ambiental e Urbanístico pela Anhanguera), São Paulo, 2011.

5 SILVA, T. C. da. A Consultoria Jurídica: Diagnóstico de Viabilidade de Empreendimentos urbanos em Florianópolis. Monografia (Pós-graduação em Direito Ambiental e Urbanístico pela Anhanguera), São Paulo, 2011.

${ }^{6}$ BRASIL. Legislação Brasileira de Direito Ambiental e Constituição Federal. 1a ed. São José: Conceito 
Já o Código Civil brasileiro regulamenta a responsabilização a todo aquele que causar dano a outrem:

Artigo 927. Aquele que, por ato ilícito (arts. 186 e 187), causar dano a outrem, fica obrigado a repará-lo.

Parágrafo único. Haverá de reparar o dano, independentemente de culpa, nos casos especificados em lei, ou quando a atividade desenvolvida pelo autor do dano implicar, por sua natureza, risco para os direitos de outrem. ${ }^{7}$

Tais artigos, se combinados com a Política Nacional do Meio Ambiente, regulamentada pela Lei 6.938/81, trazem à pessoa jurídica a obrigação da reparação civil pelo dano ambiental praticado. Importante salientar que além da reparação do dano em si, as sanções impostas ao infrator têm o objetivo de inibi-lo de sequencialmente permanecer nas referidas práticas infratoras.Desta forma, a penalização é entendida como meio de reeducação ambiental.

Importante salientar que a respeito de tal responsabilidade, irrelevante é a subjetividade, a intenção de causar o dano ambiental porquanto que, uma vez identificado o dano em virtude da obra civil, indiscutivelmente o construtor será responsabilizado, civil, administrativa e penalmente e quiçá sofrerá também entraves em processos licitatórios dentre outros, conforme a dimensão do dano ocasionado. Além disso, tal responsabilidade é ampla, atingindo também as pessoas físicas partícipes, autores e coautores, como por exemplo, o administrador da empresa infratora, consoante a Lei de Crimes Ambientais.

Desta forma, percebe-se a grande importância dada pelo ordenamento jurídico pátrio às questões ambientas, as quais deverão ser respeitadas pelos empreendimentos urbanos, sob pena de sofrerem as consequências sancionatórias pertinentes ${ }^{8}$. É necessário que se diga que pelo motivo de determinados vícios estejam arraigados em uma sociedade, estes não criam leis por si próprios, não possuem poder de revogar as leis existentes, muito menos o que a Constituição dita.

Editorial, 2009, p. 1035.

7 BRASIL. Código Civil Brasileiro. Disponível em: http://www.planalto.gov.br/ccivil_03/leis/2002//10406.htm. Acesso em 10 de março de 2015.

8 SILVA, T. C. da. A Consultoria Jurídica: Diagnóstico de Viabilidade de Empreendimentos urbanos em Florianópolis. Monografia (Pós graduação em Direito Ambiental e Urbanístico pela Anhanguera), São Paulo, 2011. 


\section{TEORIA DO RISCO INTEGRAL}

O conceito de risco, comumente estudado e debatido na sociedade atual, é também aplicado ao Direito Ambiental. Segundo a Teoria do Risco Ambiental, irrelevante a discussão em responsabilidade direta ou indireta, pois neste caso, diferença não há entre aqueles autores diretos do dano ambiental daqueles meros contribuintes. Nesse caso, inexistem excludentes, tampouco atenuantes para vias de responsabilização legal. Conforme Guivant: ${ }^{9}$

Nesta última década, o conceito de risco passou a ocupar um lugar central na teoria social. Dois dos mais importantes e influentes teóricos sociais contemporâneos, Ulrich Beck e Anthony Giddens, contribuíram, decisivamente, para isto, ao considerarem os riscos, em especial os ambientais e tecnológicos de graves consequências, como chaves para entender as características, os limites e transformações do projeto histórico da modernidade.

Ainda a autora mencionada pontua o caráter desafiador do descobrimento de meios controladores dos riscos ${ }^{10}$ :

Por último, outro desafio aponta as alternativas para o controle dos riscos. Observou-se neste artigo que diversos autores comentados levantam a necessidade de aceitar as incertezas, ambiguidades e áreas desconhecidas e não previstas em torno dos riscos. Embora, por isto, as análises qualitativas pareçam cair num terreno de alternativas difusas, trata-se de um desafio inevitável a ser enfrentado pelos atores, sejam leigos ou peritos, envolvidos nas diversas fases dos riscos. Como diz Beck, lidar com os riscos exige uma forma de atuar que aceite a ambivalência das práticas sociais, sem apelos a soluções definitivas.

Esse dispositivo é aplicado no direito ambiental, pois por trás da questão pontual ensimesmada, está o intuito de salvaguardar a proteção do próprio planeta, em uma discussão ética ambiental ${ }^{11}$. Conforme José Rubens Morato Leite

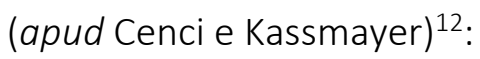

\footnotetext{
9 Guivant, Julia S. A Trajetória das Análises de Risco: Da Periferia ao Centro da Teoria Social. Revista Brasileira de Informações Bibliográficas - ANPOCS, São Paulo, n. 46, p. 3-38, 1998.

10 Guivant, Julia S. A Trajetória das Análises de Risco: Da Periferia ao Centro da Teoria Social. Revista Brasileira de Informações Bibliográficas - ANPOCS, São Paulo, n. 46, p. 3-38, 1998.

11 SILVA, T. C. da. A Consultoria Jurídica: Diagnóstico de Viabilidade de Empreendimentos urbanos em Florianópolis. Monografia (Pós graduação em Direito Ambiental e Urbanístico pela Anhanguera), São Paulo, 2011.

12 CENCl, Daniel Rubens. KASSMAYER, Karin. O Direito Ambiental na Sociedade de Risco e o
} 
O Estado de Direito Ambiental traz consigo um típico direito pósmoderno, fruto da sociedade científico-técnico-industrial e de risco. Diversamente do que ocorre com os tradicionais direitos sociais, que visam compulsoriamente e positivamente a criar e realizar o que não existe (habitação, serviço de saúde), o Estado de Direito Ambiental diz respeito a um perfil modificado de direito social, exigindo, fundamentalmente, ações de cidadania compartilhada entre Estado e cidadãos, utilizando mecanismos precaucionais, preventivos, de responsabilização, de preservação e de reconstituição.

Devido à consciência de que se vive em uma realidade pela qual, o crescimento econômico, o aumento populacional mundial dentre outras variantes que condicionam à eterna eminência de que catástrofes sejam possíveis, muitos doutrinadores e pesquisadores definem a sociedade atual como de risco. Nesse aspecto, a análise crítica Leite e Canotilho ${ }^{13}$ :

A sociedade de risco é aquela que, em função de seu contínuo crescimento econômico, pode sofrer a qualquer tempo as consequências de uma catástrofe ambiental. Nota-se que, portanto, a evolução e o agravamento dos problemas, seguidos de uma evolução da sociedade (da sociedade industrial para a sociedade de risco), se, contudo, uma adequação dos mecanismos jurídicos de solução dos problemas dessa nova sociedade. Há consciência da existência dos riscos, desacompanhada, contudo, de políticas de gestão, fenômeno denominado irresponsabilidade organizada.

O que se discute, nesse novo contexto, é a maneira pela qual podem ser distribuídos os malefícios que acompanham a produção de bens, ou seja, verifica-se a autolimitação desse tipo desse tipo de desenvolvimento e a necessidade de redeterminar os padrões (estabelecer novos padrões) de responsabilidade, segurança, controle, limitação e consequência do dano. A isso tudo, porem, somam-se os limites científicos de previsibilidade, quantificação e determinação dos danos. Isso porque se deve atentar para as limitações da ciência no tocante à previsibilidade, quantificação e determinação de danos.

A construção civil, por ser atividade passível de gerar impactos ambientais negativos, está condicionada aos princípios constitucionais do desenvolvimento sustentável, responsabilidade social, bem como se aplica a teoria do risco integral,

Conceito da Justiça Ambiental. http://anppas.org.br/encontro4/cd/ARQUIVOS/GT11-1015-88620080510203835.pdf. Acesso em 28 de nov. 2011.

13 LEITE, José Rubens Morato, CANOTILLO, José Joaquim. Sociedade de Risco e Estado. LEITE, José Rubens Morato, CANOTILLO, José Joaquim. Direito Constitucional Ambiental Brasileiro. São Paulo: Saraiva, 2007, p. 130-154.

Ignis | Caçador | v.6 | n.1 | p. 143-169 | jan./abr. 2017 
dentre outros. É necessário que se diga que além do iminente risco presente no referido seguimento, não menos importante é o risco que o próprio empreendedor pela imprevisão e desconhecimento inerente de um empreendimento carente de respaldo técnico na área da biologia, jurídica e etc. Diante da pequena abordagem principiológica a qual o direito ambiental está embasado é que um diagnóstico jurídico especializado se faz de suma importância como forma de evitar problemas ambientais, bem como judiciais para o ramo da construção civil.

\section{A REALIDADE DO MUNÍCIPIO DE CAÇADOR}

O município de Caçador, localizado no Alto Vale do Rio do Peixe, possui uma topografia acidentada, com a presença de vales, colinas, chapadas e morros, cuja altitude média é de 1.000 metros $^{14}$. Caçador é município preponderantemente urbano. Possui uma urbanização expressiva com taxa superior a média das cidades brasileiras, consoante pesquisa de IDH (Índice de Desenvolvimento Humano) ${ }^{15}$. Na referida pesquisa consta planilha detalhando a população total entre homens e mulheres pertencentes à área rural, bem como a taxa de urbanização. Em tal trabalho consta que no ano de 2010 a taxa de urbanização chegou ao patamar de $91,09 \%$. Desta forma percebe-se a acelerada urbanização local. Vejamos ${ }^{16}$ :

\begin{tabular}{|l|r|r|r|r|r|r|}
\hline População Total, por Gênero, Rural/Urbana e Taxa de Urbanização - Caçador - SC \\
\hline População & $\begin{array}{r}\text { População } \\
\text { (1991) }\end{array}$ & $\begin{array}{r}\text { \% do Total } \\
\mathbf{( 1 9 9 1 )}\end{array}$ & $\begin{array}{r}\text { População } \\
\text { (2000) }\end{array}$ & $\begin{array}{r}\text { do Total } \\
\text { (2000) }\end{array}$ & $\begin{array}{r}\text { População } \\
\text { (2010) }\end{array}$ & $\begin{array}{r}\text { \% do Total } \\
\text { (2010) }\end{array}$ \\
\hline População total & 50.515 & 100,00 & 63.322 & 100,00 & 70.762 & 100,00 \\
\hline Homens & 25.089 & 49,67 & 31.667 & 50,01 & 35.040 & 49,52 \\
\hline Mulheres & 25.426 & 50,33 & 31.655 & 49,99 & 35.722 & 50,48 \\
\hline Urbana & 43.237 & 85,59 & 55.542 & 87,71 & 64.457 & 91,09 \\
\hline Rural & 7.278 & 14,41 & 7.780 & 12,29 & 6.305 & 8,91 \\
\hline Taxa de \\
Urbanização
\end{tabular}

Referida informação coaduna-se com o IBGE 2015. Segundo este, em

\footnotetext{
14 Prefeitura Municipal de Caçador. Disponível em: http://www.cacador.sc.gov.br/portalhome/index.php/cidade. Acesso em: 10 de março de 2015.

15 Notícia Hoje. Disponível em: http://noticiahoje.net/noticias/com-crescimento-de-22-30-em-10anos-idhm-de-cacador-e-0-735. Acesso em 28 de fevereiro de 2015. 16 Idem.
} 
2010 a população estimada do Município de Caçador foi de 70.762 (setenta mil, setecentos e sessenta e dois) habitantes, aumentando em 2014 para 75.048 (setenta e cinco mil e quarenta e oito) ${ }^{17}$. Dessa forma, trata-se de cidade em cristalina expansão populacional e por via de consequência, expansão na construção civil. Neste contexto, imperioso ater-se ao potencial problema das obras civis, em se tratando das questões ambientais.

\section{O EXEMPLO DE FLORIANÓPOLIS, CAPITAL CATARINENSE}

Tem-se como exemplo de urbanismo desenfreado o qual está eivado de questões jurídicas ambientais, a capital catarinense. A ilha de Santa Catarina, assim como a maioria das capitais e das grandes cidades brasileiras, teve incentivo do governo federal, através do Sistema Financeiro de Habitação para expandir o mercado imobiliário, onde, correlacionado à sua expansão urbana, nasce os problemas ambientais locais, já que a Administração Pública apresenta restrições às construções civis de forma tímida, pouco ou nada preocupada com as questões ambientais primando apenas pelos bons resultados econômicos, como bem esclareceu Campos $^{18}$. Cita-se Silva ${ }^{19}$ :

Esse comportamento originou no local, um "esquecimento" por parte dos empreendedores em garantir a satisfação do meio ambiente sadio, realizando seus projetos sem a devida preocupação.

Daí a cultura local dos empreendedores da área civil estar pouco comprometida com as questões ambientais, onde ainda nos dias de hoje, poucos se atêm para as questões ambientais envolvidas, apenas após terem vivenciados entraves administrativos e ou jurídicos, num

17

IBGE.

Disponível

em:

http://www.cidades.ibge.gov.br/xtras/perfil.php?lang=\&codmun=420300\&search=santacatarina|cacador Acesso em 28 de fevereiro de 2015.

18 Cabe ressaltar também, que, no período pouco havia em termos de restrições urbanísticas e ambientais por parte do poder público municipal, a não ser o Plano Diretor de 1955, que nada mencionava a respeito de meio ambiente. Pelo contrário, era dado até certo incentivo por parte dos gestores públicos municipais para o desenvolvimento das construções verticais, pois, essas obras, geravam empregos e deixavam a cidade com a cara de um grande centro urbano, o que era incentivado pelo governo pós-64, que desejava criar diversos centros metropolitanos no Brasil. CAMPOS, Edson Telê. A Expansão Imobiliária e seus Impactos Ambientais em Florianópolis. Editora Insular, 2004 p. 115.

19 SILVA, T. C. da. A Consultoria Jurídica: Diagnóstico de Viabilidade de Empreendimentos urbanos em Florianópolis. Monografia (Pós graduação em Direito Ambiental e Urbanístico pela Anhanguera), São Paulo, 2011. 
pernicioso vício cultural.

Se no princípio deu-se início ao desmatamento e ao lançamento dos seus dejetos no mar e nos rios e posteriormente com a ocupação dos morros, bem como com a crescente urbanização voltada para o turismo, foi-se estabelecendo um crescimento acelerado do ramo da obra civil, de forma desenfreada e pouco comprometida com as questões ambientais. A respeito do turismo local cita-se SONAGLIO E BUENO 20 :

Cerca de $42 \%$ do território da Ilha de Santa Catarina é constituído por áreas de preservação permanente e o crescimento urbano segue a estrutura da rede viária, faz-se necessário, então, um planejamento urbano que vise à qualidade de vida e o desenvolvimento sustentável.

A respeito das características naturais de Florianópolis, segundo a FLORAM $^{21}$ - Fundação Municipal do Meio Ambiente de Florianópolis, aponta na capital catarinense como sendo um dos seus principais exemplos de crimes em matéria ambiental, a destruição e danificação das florestas localizadas nas unidades de preservação permanente, as vegetações típicas dos mangues, bem como a construção em espaços inapropriados.

Wedy, Rossetto, Beck e Johnson (2009), em artigo que objetiva analisar a eficácia da intervenção do Ministério Público, como forma de prevenir e ou reparar os danos ambientais causados na Ilha de Santa Catarina, mais precisamente na Bacia Hidrográfica da Lagoa da Conceição, esclarecem que existem seis unidades de conservação, porém todas ameaçadas pela urbanização 22 .

Este é apenas um exemplo dos vários problemas enfrentados diante de uma urbanização desenfreada, realidade que vem gerando uma série de processos administrativos e ou judiciais em face de construtoras e proprietários de imóveis, cujas construções, ferem as boas e obrigatórias condições de saneamento básico,

20 SONAGLIO, Kerlei Eniele, BUENO, Liane da Silva. O Turismo Sustentável, o Zoneamento do Uso e Ocupação do Solo e a Especulação Imobiliária. SONAGLIO, Kerlei Eniele, FABBRIS, Cristine. Turismo Reflexões e Desafios de Um Fenômeno Contemporâneo. São Paulo: Livrus, 2010, p. 153-171.

21 Disponível em:http://www.pmf.sc.gov.br/entidades/floram/index.php?pagina=home\&menu=0. Acesso em: 06 de agosto de 2011.

22 WEDY, Lia Mara, ROSSETTO, Adriana Marques, BECK, Liciana Cariam, JOHNSON, Guillermo Alfredo. A Desconstrução do Espaço na Lagoa da Conceição - Uma Análise dos Danos Ambientais Com Base Em Instrumento Jurídico. Florianópolis, p. 199. 
de distância mínima legal das águas, das dunas e assim por conseguinte. A partir de uma maior fiscalização, bem como de uma atuação mais incisiva do Ministério Público, o ramo da construção civil vem sendo obrigado a se adequar às exigências legais ambientais, diante das frequentes consequências administrativas e jurídicas que vem sofrendo. Nesse contexto e com enfoque na realidade da construção civil, necessita-se pesquisar o comportamento da expansão imobiliária local, suas características, problemas enfrentados e o que a falta ou a presença de respaldo jurídico especializado proporciona.

Segundo Campos (apud Silva) ainda sobre a ilha de Santa Catarina ${ }^{23}$ :

Florianópolis, até os anos sessenta, era uma cidade pacata, com um fluxo de turistas ainda nascente, com poucas construções verticais e com uma paisagem típica de uma cidade provinciana. Porém, nos anos 70, nessa notável ascensão econômica, com o crescimento médio em torno de 10\%a.a., o que, consequentemente, refletiu na economia catarinense, que nessa fase vinha com baixo nível de desemprego, e baixa taxa de inflação, fez com que, desse período de grande desenvolvimento econômico, fosse, também, beneficiária a indústria da construção civil, em toda Santa Catarina, e, principalmente, a de Florianópolis (CAMPOS, 2004).

O referido autor correlaciona a expansão urbana de Florianópolis com os problemas ambientais locais, fomentada pela participação omissa por parte da Administração Pública local pouco ou nada preocupada com as questões ambientais, primando apenas pelos bons resultados econômicos.

\section{JULGADOS A RESPEITO}

Expressiva é a gama de processos envolvendo infrações e danos ambientais na construção imobiliária de Florianópolis e arredores. Diante disso elencamos alguns poucos exemplares de julgados: Construção civil em área de preservação permanente. Aplicação de multa majorada pelas condições locais, não obstante autorização prévia ${ }^{24}$

\footnotetext{
${ }^{23}$ CAMPOS, Edson Telê. A Expansão Imobiliária e seus Impactos Ambientais em Florianópolis: Editora Insular, 2004, p. 113.

24 BRASIL. Tribunal Regional Federal da 4a Região. Ação Civil Pública. Matéria Ambiental. Empreendimento construído com base em autorização judicial em área de preservação permanente. Situação consolidada. Responsabilidade. Multa indenizatória. AC 2003.72.08.002409-
} 
EMENTA: ADMINISTRATIVO. AÇÃO CIVIL PÚBLICA. DANO AMBIENTAL. EMPREENDIMENTO CONSTRUÍDO COM BASE EM AUTORIZAÇÃO JUDICIAL EM ÁREA DE PRESERVAÇÃO PERMANENTE. SITUAÇÃO CONSOLIDADA. RESPONSABILIDADE. MULTA INDENIZATÓRIA. Considerando que o empreendimento foi construído sobre pequena área da faixa de proteção do rio, em área de preservação permanente, ainda que mínima, que o referido rio está degradado pela ação da própria comunidade em geral, e não pela construção em si; que a construção foi autorizada judicialmente, mediante decisão proferida em âmbito de agravo de instrumento, que a obra está em zona urbana e que respeita o alinhamento de outros prédios que já existem há décadas no local, a remoção da obra é sanção desproporcional, em face da situação consolidada. Imposição de sanção pecuniária é a que melhor se amolda ao ilícito, que, tendo em conta os parâmetros da proporcionalidade em relação ao dano, ao valor da obra (alto valor imobiliário por se tratar de bem à beira-mar em local de potencial turístico relevante), ao valor da causa, e a desídia dos réus em relação à elaboração do PRAD, impondo-se a majorada da multa para R\$ $500.000,00$. Tratando-se de direito difuso, a reparação civil ambiental assume grande amplitude, com profundas implicações na espécie de responsabilidade do degradador que é objetiva, fundada no simples risco ou no simples fato da atividade danosa, independentemente da culpa do agente causador do dano. (TRF4, AC 2003.72.08.002409-5, Quarta Turma, Relator Jorge Antônio Maurique, D.E. 20/05/2011), (grifo nosso)

Multa administrativa mantida em apelação em decorrência de infração ambiental cometida por construtora. Cancelamento de Alvará. Demolição integral das obras ${ }^{25}$

\author{
EMENTA \\ ADMINISTRATIVO. IBAMA. AUTO DE INFRAÇÃO E AUTO DE EMBARGO. \\ PROCEDÊNCIA PARCIAL DA DEMANDA PARA AFASTAR A INTERDIÇÃO \\ DA OBRA MANTIDA A EXIGÊNCIA DA MULTA POR INFRAÇÃO
}

5. Relator: Jorge Antônio Maurique. Porto Alegre, RS, 20 de maio de 2011. Disponível em: http://jurisprudencia.trf4.jus.br/proxy/public/index.php?q=responsabilidade+construtora+dano+am biental\&btnG=Pesquisar\&partialfields=\%28id_tipo\%3A1\%7Cid_tipo\%3A3\%7Cid_tipo\%3A2\%29\&req uiredfields=\&as_q=\&client=juris_int\&output=xml_no_dtd\&proxystylesheet=juris\&oe=UTF-

8\&ie=UTF-8\&ud=1\&exclude_apps=1\&sort=date\%3AD\%3AS\%3Ad1\&filter=0\&getfields=*\&site=juris . Acesso em: 09 de agosto de 2011.

25 BRASIL. Tribunal Regional Federal da 4ạ Região. Auto de Infração e Auto de Embargo. Apelação/Reexame Necessário № 2006.72.00.003377-4/SC. Matéria Ambiental. Procedência parcial da demanda para afastar a interdição da obra mantida a exigência da multa por infração ambiental. Relator: Sérgio Renato Tejada Garcia. Porto Alegre, RS, 20 de maio de 2011. Disponível em: http://www.trf4.jus.br/trf4/jurisjud/inteiro_teor.php?orgao=1\&documento=3730289\&termosPesq uisados=responsabilidade|construtora|dano|ambiental Acesso em: 09 de agosto de 2011.

Ignis | Caçador | v.6 | n.1 | p. 143-169 | jan./abr. 2017 
AMBIENTAL A manutenção da exigência da multa se impõe porque a infração administrativa decorre de empreendimento imobiliário lesivo ao meio ambiente. Autorizada a execução do loteamento mediante aprovação da prefeitura municipal, restando consumada a urbanização da área e tendo sido deferida a tutela antecipada, mostra-se inviável após o transcurso do tempo determinar o embargo das construções já realizadas. Contrato de Permuta Nulo, Cancelamento de Alvará de licença para a construção civil em face da Ilegalidade Apurada, demolição integral das edificações, sob pena de multa diária.

EMENTA

ÁREA PÚBLICA DE PRESERVAÇÃO AMBIENTAL CONSTRUÇÃO EM ÁREA DE FAIXA DE PRAIA. DANO AO MEIO AMBIENTE. LEI 7.661/88( PNBC). DECRETO 5.300/2004. ZONA COSTEIRA. É fato que a construção encontra-se apenas a 10 (dez) metros da linha do mar, avançado sobre aquilo que, costumeiramente, é chamado de faixa de praia. O Plano Nacional de Gerenciamento Costeiro (PNGC - Lei no 7.661/88), datado de 1988, ainda que regulamentado tão-somente em dezembro de 2004, quando expedido o Decreto no 5.300, apresentava determinações que exigiam dos Estados e Municípios - com competência legislativa concorrente - que, evidentemente, não promovessem, na falta da regulamentação federal, ações contrárias às preocupações traduzidas na referida Lei. De seu conteúdo extraem-se disposições legais que tratam de impor, mediante regra de reforço, que a lei está, em alguns de seus aspectos, desde a sua publicação, com seu conteúdo válido e exigível, independentemente de omissões regulamentares das autoridades do poder executivo. A construção de obra com proximidade excessiva da linha do mar, ferindo e privatizando a área de praia, é contrária à disposição expressa da Lei 7.661/88, pois "Art. 10. As praias são bens públicos de uso comum do povo, sendo assegurado, sempre franco acesso a elas e ao mar, em qualquer direção e sentido. § 1‥ Não será permitida a urbanização ou qualquer forma de utilização do solo na Zona Costeira que impeça ou dificulte o acesso assegurado no caput deste artigo." Outrossim, consta do § 3 o do art. 10 da Lei no 7.661/88:"Entende-se por praia a área coberta e descoberta periodicamente pelas águas, acrescida da faixa subsequente de material detrítico, tal como areias, cascalhos, seixos e pedregulhos, até o limite onde se inicie a vegetação natural, ou, em sua ausência, onde comece um outro ecossistema". Frente a esse quadro legislativo, as ascensões de qualquer espécie na faixa de praia, com ofensa à possibilidade de fruição por parte de toda a sociedade, não podem ser toleradas, por ser considerada bem público. Se for o caso, devem os proprietários ser indenizados pelas municipalidades que as autorizaram, porém a situação não pode ser coonestada. Notadamente no caso em apreço, onde a obra é posterior a Lei no 7.661/88, dado que o alvará foi concedido em 01.08.95.

ACÓRDÃO

Vistos e relatados estes autos em que são partes as acima indicadas, decide a Egrégia 4a Turma do Tribunal Regional Federal da 4a Região, por unanimidade, negar provimento ao apelo, nos termos do relatório, 
votos e notas taquigráficas que ficam fazendo parte integrante do presente julgado.

Porto Alegre, 18 de novembro de 2009. Juiz Federal MÁRCIO ANTÔNIO ROCHA.

\section{Relator}

\section{RELATÓRIO}

Trata-se de ação civil pública, com pedido de liminar, ajuizada pelo Ministério Público Federal, por meio da qual pretende obstar apontado dano ao meio ambiente em razão da ocupação ilegal de área pública, de preservação ambiental (terreno de marinha), na região de Retiro dos Padres, no Município de Bombinhas/SC, em que foi construído o empreendimento xxxxxxxx. Requer: sejam suspensos os efeitos dos alvarás de licença n. 550 e 937, concedidos pela Secretaria de Planejamento, Obras e Saneamento da Prefeitura Municipal de Bombinhas/SC; seja determinado aos réus .......... que se abstenham de adotar quaisquer atos, relacionados à execução de obras no imóvel, objeto da demanda; seja cominada multa diária pelo descumprimento da liminar a ser concedida; seja notificada a União para que integre o polo ativo se quiser; seja reconhecida a nulidade do contrato de permuta, firmado pelos réus ; sejam cancelados os alvarás de licença acima mencionados e o Parecer n. 50 F 95, expedido pela Fundação de Amparo à Tecnologia e ao Meio Ambiente-FATMA; sejam canceladas as inscrições imobiliárias, existentes junto à Secretaria de Patrimônio da União, por comprometerem a integridade das áreas de uso comum do povo; seja assegurada a demolição das edificações em alvenaria do empreendimento denominado "Retiro do Sol Nascente"; seja, totalmente, recuperada a área ambiental, objeto da agressão. Deferida a liminar para: suspender os efeitos dos alvarás de licença n.o 550 e 937 (fl. 305), concedidos pela secretaria de Planejamento, Obras e Saneamento do Município de Bombinhas/SC; determinar aos réus..... que se abstenham de quaisquer atos relativos à execução do empreendimento, objeto da ação; determinar a notificação da União para que, se quiser, integre o polo ativo da relação processual. Oportunizada a produção de prova. Feito devidamente instruído. Sentenciando (fls. 1161/1180), o Juízo a quo julgou procedente o pedido para efeito de:

(a) declarar nulo o contrato de permuta, firmado pelos réus

(b) cancelar, em face da reconhecida ilegalidade, os alvarás de licença para a construção civil n.os 550 e 937 (fls.101/102), expedidos pela Prefeitura de Bombinhas/SC;

(c) cancelar, por flagrante ilegalidade, o Parecer n.o 50 F 95 (fl. 104), expedido pela FATMA;

(d) declarar legal o cancelamento - efetuado pela Secretaria de Patrimônio da União - das inscrições imobiliárias que se encontram em nome de e de por estarem as ocupações concorrendo para comprometer a integridade das áreas de uso comum do povo, de preservação ambiental, necessárias à proteção dos ecossistemas naturais; 
(e) condenar a ré

Construtora e Incorporadora Ltda. a proceder, as suas expensas, à demolição integral das edificações de alvenaria do empreendimento Retiro do Sol Nascente, e à recuperação total da área degradada, resguardado o direito de regresso contra os demais réus pelos gastos com a demolição, sem exclusão dos demais direitos que possa vir pleitear em juízo. Estipulado prazo de 90 dias para efetivação da demolição, bem como fixada multa diária de $\mathrm{R} \$$ 1.000,00 (um mil reais) pelo descumprimento da ordem. Verba honorária, fixada em $10 \%$ do valor da causa, a ser suportada pelos réus, pro rata. Peticiona a Ré Construtora e Incorporadora Ltda. a juntada ao feito de cópia de processo-crime (inquérito policial), ajuizado perante a Justiça Federal de Itajaí, pela Justiça Pública contra seus diretores, para fim de apuração de responsabilidades criminais relativamente aos fatos que ensejaram a presente ação civil pública (fls. 1192/1638). Rejeitados os embargos de declaração que foram opostos (fls. 1656/1660). FATMA interpõe apelo, requerendo a exclusão de parte dispositiva da sentença, relacionada ao direito regressivo da ré contra o órgão ambiental estadual, quanto aos gastos com a demolição (fl. 1663/1669). Os réus

Construtora e Incorporadora Ltda. requerem a reforma integral da sentença, julgando-se improcedente o pleito (fls. 1670/1694). Após apresentação de contrarrazões, requerem os réus a juntada de novos documentos (fl. 1800), tendo o Ministério Público Federal emitido parecer no sentido de que não sejam providos os recursos (fls. 1809/2824). Em Sessão, ocorrida em 7/7/2004, o Relator pediu adiamento do julgamento (certidão fl. 1859). Levado em mesa, em 22/9/2004, a Quarta Turma deste Tribunal, por unanimidade, negou provimento aos apelos (fls. 1860/1875). Em Sessão, ocorrida em 10/0/2005, restaram acolhidos, em parte, os embargos de declaração, opostos por ................ e outros, apenas para fim de prequestionamento (fls.1884/1888). Em Sessão, ocorrida em 22/6/2005, foram acolhidos novos embargos de declaração para fim de prequestionamento (1904/1906). Em Sessão, ocorrida em 30/8/2006, a Quarta Turma, mais uma vez, rejeitou novos embargos de declaração (fls. 1919/1922). ........................ e outros interpõem recursos especial (fls. 1925/1959) e extraordinário (fls. 1962/2001). No Superior Tribunal de Justiça, a Segunda Turma deu provimento ao REsp no 943.858/SC, determinando o retorno dos autos a este Tribunal para nova inclusão em pauta de julgamento, assegurando-se sustentação oral pelo patrono dos recorrentes (fls. 2060/2065). (grifo nosso)

Acúmulo de matéria orgânica, não exigência de EIA pelos órgãos ambientais, imediata paralisação das obras e publicação em jornais de circulação sob pena de multa 26

26 BRASIL. Tribunal Regional Federal da 4ạ Região. AÇÃO CIVIL PÚBLICA № 2003.72.00.007539-1/SC. 


\section{DISPOSITIVO}

Ante o exposto, JULGO PROCEDENTES os pedidos constantes da inicial, extinguindo o processo com fulcro no art. 269, inciso I, do Código de Processo Civil, para ratificar os termos da liminar concedida, e condenar o Município de Florianópolis a: a) determinar o total cumprimento, por seus órgãos e agentes, da legislação federal e estadual sobre a faixa de proteção ao redor do elemento hídrico, bem como a providenciar levantamento de todas as ocupações em faixa de marinha, no entorno da Lagoa da Conceição, identificando os responsáveis, indicando quais obtiveram alvarás e qual a data dos mesmos e adotando as providências cabiveis para a abertura de acessos às margens da mesma, especialmente na faixa definida pelo Código de Águas e pela Lei do Plano Diretor dos Balneários (15 metros); b) divulgar esta sentença em jornal de grande circulação estadual, haja vista o caráter educativo que deve acompanhar as ações de defesa do meio ambiente; c) pagar a pena pecuniária de $R \$ 10.000,00$ (dez mil reais) por cada caso de descumprimento da decisão; revertendo-se os valores para o Fundo de Reconstituição de Danos Ambientais, previsto no art. 13, da Lei no $7347 / 85$. O pagamento da multa relativa ao descumprimento da liminar fica postergado à fase executória, conforme decisão de fls. 736 e vo. Sem honorários, nos termos da fundamentação. Condeno o réu ao pagamento das custas e despesas processuais. Eventual recurso interposto será recebido apenas no efeito devolutivo (art. 14, da Lei 7347/1985), valendo o presente como recebimento do mesmo em caso de preenchimento dos pressupostos de admissibilidade. Preenchidos estes, dê-se vista à parte contrária para apresentação de contra-razões, com posterior remessa ao TRF da 4a Região. Publique-se. Registre-se. Intimem-se. Após o trânsito em julgado, arquivem-se os autos com as baixas necessárias. Florianópolis, 05 de novembro de 2009. GUY VANDERLEY MARCUZZO, Juiz Federal. (grifo nosso).

\section{Interdição de Obras Pela Polícia Ambiental ${ }^{27}$}

Ainda, cita-se notícia publicada em jornal de circulação do estado de Santa Catarina, através de seu site a respeito de interdições de obras de condomínio localizado em praia de Florianópolis, em decorrência de retirada de água do terreno sem as devidas licenças. Abaixo, a questão como foi noticiada:

\footnotetext{
Matéria Ambiental. Acúmulo de Matéria Orgânica. Não Exigência de EIA pelos Órgãos Ambientais. Cautelar Deferida Pela Imediata Paralisação das Obras. Sentença Procedente. Efeitos da Liminar Mantida. Juiz: Guy Vanderley Marcuzzo. Caçador, SC, 05 de novembro de 2009. Disponível em: http://www.clicrbs.com.br/pdf/7814985.pdf. Acesso em: 29 de setembro de 2011.

27 Diário Catarinense. A construtora drenava o terreno sem autorização. Caçador: 2011. Disponível em:<

http://www.clicrbs.com.br/diariocatarinense/jsp/default.jsp?uf=2\&local=18\&section=Geral\&news $\mathrm{D}=\mathrm{a} 3240795 . x \mathrm{ml}$. . Acesso em: 29 de setembro de 2011.
} 
Polícia Militar Ambiental interdita obras de residencial no Campeche, em Florianópolis.

A construtora drenava o terreno sem autorização.

A Polícia Militar Ambiental interditou as obras do residencial XXXX, em Florianópolis, porque a construtora estava drenando o terreno sem autorização. Foi lavrado um auto de infração e os empreendedores devem procurar os órgãos ambientais para conseguir licenças que autorizem a retirada d'água. Enquanto isto não ocorrer, o embargo permanece. O Ministério Público Federal foi avisado sobre a interdição para o caso de querer tomar alguma providência. Todas as outras licenças estavam corretas. A Polícia Militar Ambiental informou que descobriu a irregularidade através de uma denúncia. A obra mobilizou moradores da Praia do Campeche. Houve campanha em redes sociais e entidades comunitárias para o embargo do empreendimento. (grifo nosso)

\section{O DIAGNÓSTICO JURÍDICO PRÉVIO}

Diante do que se abordou, clara a importância de uma consultoria jurídica especializada como forma de salvaguardar os empreendimentos atrelados à construção civil de incorrerem no erro de investir em obras dissociadas dos ditames legais ambientais. Nesse contexto, Silva apud Millaré 28 :

A Constituição Federal de 1988, em seu art. 133, consagrou o papel do advogado como indispensável à administração da Justiça. Nesse amplo espectro se enquadra o que se convencionou chamar Justiça Ambiental (MILLARÉ, 2007).

Vivemos em tempos de incertezas e inseguranças, sobretudo no que tange as questões ambientais; não raro informações equivocadas dos próprios órgãos e até mesmo de licenças impróprias dadas por aqueles que deveriam esclarecer e nortear o empreendedor e ao invés disso, contribuem para a realização de obras desassociadas dos parâmetros legais e em via de consequência, sofrem embargos, demolições, multas expressivas e até mesmo obrigação de publicação do ocorrido nos jornais de grande circulação, eivando o empreendimento e sua imagem. Nesse contexto é que se faz de suma necessidade o aporte advocatício aos às obras civis.

28 SILVA, T. C. da. A Consultoria Jurídica: Diagnóstico de Viabilidade de Empreendimentos urbanos em Florianópolis. Monografia (Pós-graduação em Direito Ambiental e Urbanístico pela Anhanguera), São Paulo, 2011. 
A respeito ${ }^{29}$ :

O papel da advocacia frente à sociedade, à luz dos ditames da Carta de 1988, regulamentado pelas atribuições impostas no Estatuto da Advocacia, aclaram a necessidade preeminente do trabalho advocatício nos projetos com impacto ambiental. O Estatuto da Advocacia, já em seu artigo 1으. II determina serem privativas da advocacia as atividades de assessoria, consultoria e direção jurídicas, além de afirmar que presta serviço público e exerce função social (artigo2o, § 1ํ).

Porém a referida prestação jurídica deverá ser realizada a contento e alicerçada no conhecimento específico da matéria e na qualidade que se exige, pois como bem Millaré (2007) assevera, um trabalho advocatício prestado de forma negligente poderá causar consequências negativas ao cliente, sendo outro aspecto que demonstra o grau de responsabilidade social; a atuação do advogado ou a falta deste serviço será o divisor de águas para uma correta liberação da obra com viabilidade sócio econômico ambiental.

A advocacia é seguimento profissional com elevada importância social, eis que patrocina pelos interesses e direitos dos indivíduos, sobretudo em uma sociedade de estado democrático de direito. É profissão condicionada a toda e qualquer característica existente em uma sociedade, seus clamores, e suas mudanças comportamentais, razão pela qual o constituinte brasileiro viu a necessidade de ser seguimento profissional incluso na própria Constituição Federal, em seu capítulo IV - Das Funções Essenciais à Justiça, situação sui generis entre as profissões ${ }^{30}$ :

Art. 133 - O advogado é indispensável à administração da justiça, sendo inviolável por seus atos e manifestações no exercício da profissão, nos limites da lei.

Na há não como pensar a sociedade sem a inserção das atividades advocatícias em toda e qualquer situação em que o homem, individualmente ou na coletividade, bem como as pessoas jurídicas, precise regulamentar seus interesses, positivar seus direitos, bem como exercer seu direito à defesa. Desta forma o exercício da advocacia é prestação de serviço público, o que bem aclarado está no

\footnotetext{
29 Idem.

30 BRASIL. Legislação Brasileira de Direito Ambiental e Constituição Federal. 1a ed. São José: Conceito Editorial, 2009, p. 1030.
} 
estatuto profissional, o Estatuto da Advocacia e da OAB, Lei 8.906, de 04 de julho de $1994^{31}$. Neste contexto as atividades humanas que de alguma forma tocam as questões ambientais, dentre elas, a construção civil, também necessitam do respaldo dos serviços advocatícios. Sobre o assunto Franco $^{32}$, em um enfoque mais amplo, ao definir planejamento ambiental, sustenta a necessidade da atuação de profissionais nas mais diversas áreas:

Assim, pode-se considerar que Planejamento ambiental é todo o planejamento que parte do princípio da valoração e conservação das bases naturais de um dado território como base de auto - sustentação da vida e das interações que a mantém, ou seja, das relações ecossistêmicas. Para isso, o Planejamento ambiental emprega como instrumentos todas as informações disponíveis sobre a área de estudo, vindas das mais diversas áreas de conhecimento, bem como as tecnologias de ponta que possam facilitar o seu meio principal de comunicação e de projeto que é o Desenho ambiental.

Sobre a necessidade de um aporte profissional interdisciplinar, MARICATO ${ }^{33}$ destaca: "A implementação de uma nova política urbana requer a qualificação de pessoal no campo jurídico, da engenharia, do urbanismo, da arquitetura, da geografia, do meio ambiente e etc." (MARICATO, 2001). Ainda Maricato ressalta a diversidade legal no campo ambiental que o país possui o que ainda não garante que efetivamente os municípios exerçam suas funções administrativas de forma comprometida com a sustentabilidade do meio ambiente local, bem como uma sadia qualidade de vida. É bem verdade a colocação da autora, porém além da administração pública, a iniciativa privada também tem de adequar-se e gerir suas atividades quebrando os vícios econômicos e culturais, no sentido de enxergar que pode sim garantir o êxito econômico, respeitando os ditames ambientais legais.

\footnotetext{
31 Art. 2‥ O advogado é indispensável à administração da justiça.

§1‥ No seu ministério privado, o advogado presta serviço público e exerce função social. BRASIL, Lei 8.906, de 04 de julho de 1994. Estatuto da Advocacia e da OAB. Dispõe sobre o Estatuto da Advocacia e a Ordem dos Advogados do Brasil - OAB. Diário Oficial da República, p. 10. 32 FRANCO, Maria de Assunção Ribeiro. Planejamento Ambiental para a Cidade Sustentável. São Paulo: Annablume Editora, 2000, p. 35.

33 MARICATO, Ermínia. Brasil, Cidades. Alternativa para a Crise Urbana. Petrópolis: Editora Vozes, 2001, p. 76.
} 


\section{CONCLUSÃO}

O Brasil atualmente possui um emaranhado de leis de tema ambiental, nas três esferas, federal, estadual e municipal, tornando-se muito dificultoso para o empreendedor (e porque não dizer impossível) transcender todas essas dificuldades, ainda mais por desconhecer o assunto, o que obstaculiza a administrar e a fazer fluir atividades próprias pertinentes ao seu negócio. Portanto, o construtor de obras civis necessita ter o respaldo do advogado nas questões ambientais, devendo este último sempre levantar todas as minúcias pertinentes no caso concreto e aclarar as implicações que a responsabilidade objetiva acarretará para o empreendimento. Diante de tudo que fora exposto conclui-se pela necessidade do respaldo da consultoria advocatícia especializada em âmbito urbanístico e ambiental nos primórdios de um projeto da construção civil.

Não há como se ater para a problematização ambiental nos espaços urbanos, sem adentrar em como sucessivamente, durante décadas as construtoras e incorporadoras vem realizando suas atividades, onde, inexiste a preocupação em ter o acompanhamento prévio da viabilidade jurídica ambiental do empreendimento do local escolhido para sua implantação; quais são as nuances que podem ser prejudiciais; se estão à margem da ilegalidade ambiental, e consequentemente, se terão no futuro problemas como desde o embargo do projeto para a sua readequação, até sua demolição, independente da condenação penal que poderá ser atribuída.

O empresário da construção civil, apenas conseguirá obter a garantia de que seu projeto não seja eivado de entraves futuros, se estiver alicerçado dos serviços advocatícios especializados na área. Sem contar com o fato de que, embora seu projeto tenha suas licenças liberadas pelos órgãos administrativos competentes, isso não afasta consequências jurídicas futuras, caso essas licenças também tenham sido liberadas inadequadamente, o que muito ocorre, pois a falta de técnica, conhecimento nesses órgãos são muito constantes. Mais um motivo para se resguardar previamente através de uma boa assessoria especializada, evitando a insegurança que o seguimento vem enfrentando.

Em grau de primeira importância, está a própria proteção do meio ambiente e a sadia qualidade de vida local, seja esta humana, fauna e ou flora, garantia essa que, no momento em que o advogado possa orientar os atores de 
atividades de impactação ambiental negativa, estará evitando que tal atividade venha a lesar o patrimônio natural e ou artificial, ajudando a garantir que a população do entorno possa ter uma vida sadia e com qualidade. Em segundo plano estão os interesses de êxito e de expansão da atividade, não podendo mais estar dissociado do que a lei ambiental dita, e, para que conduza seu negócio de forma limpa, responsável, comprometida com a responsabilidade sócio ambiental (e porque não dizer ética), inevitavelmente terá que se servir de uma consultoria jurídica aplicada.

E por derradeiro, concluindo os motivos ensejadores na importância de uma assessoria jurídica e crendo na máxima de que todo o empreendedor almeja adquirir reconhecimento e credibilidade perante a sociedade (pelo olhar do empreendedor, a sociedade seria vista como consumidores, clientes do seu produto), lógica não há que esse mesmo empreendedor se lance às escuras em empreendimentos sem saber se terá que enfrentar problemas muitas vezes administrativos e jurídicos, e que fatalmente macularia a sua imagem.

\section{REFERÊNCIAS}

BRASIL. Código Civil Brasileiro. Disponível em:

http://www.planalto.gov.br/ccivil_03/leis/2002/I10406.htm. Acesso em 1o de março de 2015.

BRASIL, Lei 8.906, de 04 de julho de 1994. Estatuto da Advocacia e da OAB. Dispõe sobre o Estatuto da Advocacia e a Ordem dos Advogados do Brasil - OAB. Diário Oficial da Republica Federativa do Brasil. Brasília, 05 de jul. 2004.

BRASIL. Legislação Brasileira de Direito Ambiental e Constituição Federal. 1a ed. São José: Conceito Editorial, 2009.

BRASIL. Tribunal Regional Federal da 4ạ Região. Ação Civil Pública. Matéria Ambiental. Empreendimento construído com base em autorização judicial em área de preservação permanente. Situação consolidada. Responsabilidade. Multa indenizatória. AC 2003.72.08.002409-5. Relator: Jorge Antônio Maurique. Porto Alegre, RS, 20 de maio de 2011. Disponível em:

http://jurisprudencia.trf4.jus.br/proxy/public/index.php?q=responsabilidade+const rutora+dano+ambiental\&btnG=Pesquisar\&partialfields=\%28id_tipo\%3A1\%7Cid_tip o\%3A3\%7Cid_tipo\%3A2\%29\&requiredfields=\&as_q=\&client=juris_int\&output=xml 
no_dtd\&proxystylesheet=juris\&oe=UTF-8\&ie=UTF-

8\&ud=1\&exclude_apps=1\&sort=date\%3AD\%3AS\%3Ad1\&filter=0\&getfields=*\&site =juris. Acesso em: 09 de agosto de 2011.

BRASIL. Tribunal Regional Federal da 4ạ Região. Auto de Infração e Auto de Embargo. Apelação/Reexame Necessário № 2006.72.00.003377-4/SC. Matéria Ambiental. Procedência parcial da demanda para afastar a interdição da obra mantida a exigência da multa por infração ambiental. Relator: Sérgio Renato Tejada Garcia. Porto Alegre, RS, 20 de maio de 2011. Disponível em:

http://www.trf4.jus.br/trf4/jurisjud/inteiro_teor.php?orgao=1\&documento=37302 89\&termosPesquisados=responsabilidade |construtora|dano|ambiental Acesso em: 09 de agosto de 2011.

BRASIL. Tribunal Regional Federal da 4a Região. AÇÃO CIVIL PÚBLICA № 2003.72.00.007539-1/SC. Matéria Ambiental. Acúmulo de Matéria Orgânica. Não Exigência de EIA pelos Órgãos Ambientais. Cautelar Deferida Pela Imediata Paralisação das Obras. Sentença Procedente. Efeitos da Liminar Mantida. Juiz: Guy Vanderley Marcuzzo. Florianópolis, SC, 05 de novembro de 2009. Disponível em: http://www.clicrbs.com.br/pdf/7814985.pdf. Acesso em: 29 de setembro de 2011.

CAMPOS, Edson Telê. A Expansão Imobiliária e seus Impactos Ambientais em Florianópolis. Florianópolis: Editora Insular, 2004.

CENCI, Daniel Rubens. KASSMAYER, Karin. O Direito Ambiental na Sociedade de Risco e o Conceito da Justiça Ambiental. Disponível em: http://anppas.org.br/encontro4/cd/ARQUIVOS/GT11-1015-88620080510203835.pdf. Acesso em 28 de outubro de 2011.

COLOMBO, Silvana Bendler. O Princípio da Precaução do Direito Ambiental.

Disponível em http://www.franca.unesp.br/direitoambiental.pdf. Acesso em 28 de novembro de 2011.

Diário Catarinense. A construtora drenava o terreno sem autorização. Florianópolis: 2011. Disponível em:< http://www.clicrbs.com.br/diariocatarinense/jsp/default.jsp?uf=2\&local=18\&sectio $\mathrm{n}=$ Geral\&news $|\mathrm{D}=\mathrm{a} 3240795 . x \mathrm{~m}|>$. Acesso em: 29 de setembro de 2011.

FLORAM. Disponível em: http://www.pmf.sc.gov.br/entidades/floram/index.php?pagina=home\&menu=0. Acesso em: 06 de agosto de 2011.

FRANCO, Maria de Assunção Ribeiro. Planejamento Ambiental para a Cidade 
Sustentável. São Paulo: Annablume Editora, 2000.

FREITAS, Vladimir Passos de. A Constituição Federal e a Efetividade das Normas Ambientais. São Paulo: Editora Revista dos Tribunais, 2005.

GUIVANT, Julia S. A Trajetória das Análises de Risco: Da Periferia ao Centro da Teoria Social. Revista Brasileira de Informações Bibliográficas - ANPOCS, São Paulo, n. 46, p. 3-38, 1998.

IBGE. Disponível em:

http://www.cidades.ibge.gov.br/xtras/perfil.php?lang=\&codmun=420300\&search= santa-catarina|cacador Acesso em 28 de fevereiro de 2015.

LEITE, José Rubens Morato, CANOTILLO, José Joaquim. Sociedade de Risco e Estado. LEITE, José Rubens Morato, CANOTILLO, José Joaquim. Direito

Constitucional Ambiental Brasileiro. São Paulo: Saraiva, 2007.

MARICATO, Ermínia. Brasil, Cidades. Alternativa para a Crise Urbana. Petrópolis: Editora Vozes, 2001.

MILLARÉ, Édis. Direito do Ambiente. São Paulo: Revista dos Tribunais, 2007.

MUKAI, Toshio. Temas Atuais de Direito Urbanístico e Ambiental. Belo Horizonte: Editora Fórum, 2004.

Notícia Hoje. Disponível em: http://noticiahoje.net/noticias/com-crescimento-de22-30-em-10-anos-idhm-de-cacador-e-0-735. Acesso em 28 de fevereiro de 2015.

Prefeitura Municipal de Caçador. Disponível em:

http://www.cacador.sc.gov.br/portalhome/index.php/cidade. Acesso em: 1o de março de 2015.

RAFFS, Nicole Barão. O Profissional do Direito e a Justiça Ambiental, disponível em: http://www.direitonet.com.br/artigos/exibir/740/O-Profissional-do-Direito-e-aJustica-Ambiental . Acesso em: 05 de maio de 2011.

REIS, Jair Teixeira dos. Resumo de Direito Ambiental. Rio de Janeiro: Editora Impetus, 2008.

SILVA, T. C. da. A Consultoria Jurídica: Diagnóstico de Viabilidade de

Empreendimentos urbanos em Florianópolis. Monografia (Pós-graduação em

Direito Ambiental e Urbanístico pela Anhanguera), São Paulo, 2011. 
SONAGLIO, Kerlei Eniele, FABBRIS, Cristine (Orgs.). Turismo Reflexões e Desafios de Um Fenômeno Contemporâneo. São Paulo: Livrus, 2010.

SPADOTTO, Anselmo Jose; ELIAS, Natalia Domingues. Políticas públicas ambientais e responsabilidade da pessoa jurídica. Jus Navigandi, Teresina, ano 16, n. 2872, 13 maio 2011. Disponível em: <http://jus.uol.com.br/revista/texto/19097>. Acesso em: 6 ago. 2011

TEIXEIRA, H. A. T. et al. O Papel do Advogado na Auditoria e Política Ambiental, disponível em http://www.fmr.edu.br/npi_2.php. Acesso em: 04 de maio de 2011.

WEDY, Lia Mara, ROSSETTO, Adriana Marques, BECK, Liciana Cariam, JOHNSON, Guillermo Alfredo. A Desconstrução do Espaço na Lagoa da Conceição - Uma Análise dos Danos Ambientais Com Base Em Instrumento Jurídico. Florianópolis. 